\title{
ASR expansions at the level of a single glass-cement paste interface: experimental results and proposal of a reaction-expansion mechanism
}

\author{
Joaquín Liaudat $^{\mathrm{a}, *}$, Ignacio Carol ${ }^{\mathrm{a}}$, Carlos M. López ${ }^{\mathrm{a}}$, Andreas Leemann ${ }^{\mathrm{b}}$ \\ ${ }^{a}$ Department of Civil and Environmental Engineering, Universitat Politècnica de Catalunya, 08034 Barcelona, Spain \\ ${ }^{\mathrm{b}}$ Empa, Swiss Federal Laboratories for Materials Science and Technology, Überlandstr. 129, 8600 Dübendorf, Switzerland
}

\section{H I G H L I G H T S}

- New experimental setup for studying ASR expansions at aggregate-cement interfaces.

- ASR interfacial expansion curves of SL glass-cement interfaces are obtained.

- ASR products at the glass-cement interfaces are studied via SEM/EDS analyses.

- A reaction-expansion mechanism for ASR in SL glass concrete is proposed.

- The role of calcium: different swelling pressures of low- and high-Ca ASR products.

\section{A R T I C L E I N F O}

\section{Article history:}

Received 11 December 2018

Received in revised form 6 March 2019

Accepted 15 May 2019

\section{Keywords:}

Alkali-silica reaction

ASR

Concrete

Glass

Interface

Durability

\begin{abstract}
A B S T R A C T
A new experimental methodology for studying ASR expansions at the level of a single aggregatecementitious matrix interface is proposed. For this methodology, small sandwich-like specimens, with cement paste or mortar on top and bottom of a disc of soda-lime (SL) glass in the middle, are used. These specimens are placed in airtight containers with an alkaline solution and heated in an oven at $60{ }^{\circ} \mathrm{C}$. In these conditions, ASR products are formed rapidly at the interface of the disc and the cementitious matrix, inducing length changes in the specimen which are measured regularly. The morphology and composition of the ASR products are studied by means of SEM/EDS analyses. This inexpensive and very easy to replicate methodology may provide valuable information about the ASR expansion mechanisms. The specimens developed expansions of about $30 \mu \mathrm{m}$ before the SL glass got detached from the cement paste matrix. SEM/EDS analyses of the reaction products formed in between the SL glass and the cement paste matrix indicate calcium-to-silica molar ratios ranging between 1.0 and 1.5. Finally, based on the experimental results presented in this paper, as well as on other experimental and theoretical results found in the literature, a reaction-expansion mechanism for ASR in SL glass concrete is proposed.
\end{abstract}

\section{Introduction}

Alkali-Silica Reaction (ASR) expansions in concrete depend strongly on the aggregate size and grading, e.g. [1-4]. This effect can be attributed to various mechanisms of either chemical or mechanical origin, e.g. [1,5-8], usually acting simultaneously, which are very difficult to isolate in order to assess their real significance. Additionally, the complexity of concrete meso-structure, determined by the irregular geometry and large range of sizes of

\footnotetext{
* Corresponding author.

E-mail addresses: joaquin.liaudat@upc.edu (J. Liaudat), ignacio.carol@upc.edu (I. Carol).
}

the aggregates, makes it particularly difficult to study and model the ASR mechanisms.

In this context, a new test setup for studying ASR is proposed. The aim of this new methodology is to facilitate the study of ASR-induced expansions by reducing the complexity of concrete meso-structure. For this purpose, instead of studying ASR in regular concrete specimens, a new type of specimen with a single, discshaped reactive aggregate is used. In these specimens, the reactive aggregate disc is placed as a sandwich in between a cementitious matrix on both sides. In this way, two plane, symmetrical and geometrically defined interfaces between the reactive aggregate and the cementitious matrix are obtained. In this configuration, ASR products mainly precipitate at these interfaces tending to separate the aggregate disc from the cementitious matrix. Then, it is possi- 
ble to have an estimate of the expansion developed at a single interface by measuring the length change of the specimen. Furthermore, the simplicity of the geometry allows us to relate the measured expansion to the thickness and composition (measured by means of SEM and EDS analysis) of the layer of ASR products.

In a previous paper, Carles-Gibergues et al. [9] have proposed to use specimens with a similar configuration to study ASR. However, the authors limited their work to the study of the composition and morphology of the ASR reaction products at the aggregate-cement interface, without doing any measurement of the developed expansions. Later, Schlangen and Çopuroglu [10] proposed other test setup with a single aggregate-cement interface which, in principle, should have allowed them to measure the localized expansion due to ASR. To the best of the author's knowledge, however, the results of the test have never been published.

In the following Section 2, the test setup and the proposed testing methodology are described in detail for specimens made with plain cement paste as cementitious matrix and soda-lime (SL) glass as reactive aggregate. Subsequently (Section 3), test results obtained with specimens of that kind are presented and discussed. Additional results obtained with different cementitious matrices, reactive aggregates, and exposure conditions can be found in the doctoral thesis of the first author [11].

Finally, in Section 4, the results obtained with the Interfacial Expansion Tests are considered in the context of results obtained elsewhere with different testing setups and at different scale of observation. As a result a meso-scale reaction-expansion mechanism is proposed which is capable of explaining the whole set of experimental data considered.

\section{Method}

\subsection{General description}

The aim of the proposed test was to study expansions at the level of a single interface glass-cement paste due to the precipitation of ASR products. For this purpose, two kinds of cylindrical specimens of approximately $33 \mathrm{~mm}$ diameter and $66 \mathrm{~mm}$ height were used. The first type, named 'reactive specimens', involved sandwich-like specimens, with cement paste on top and bottom of a disc of reactive aggregate in the middle (Fig. 1). At both ends of the specimen, steel gauge inserts were embedded for length change measurements. The second type, called 'control specimens', involved purely cement paste specimens without reactive aggregate. Control specimens were used to assess the deformations of the matrix of cement paste, solely caused by phenomena such us drying shrinkage or thermal expansions.

After casting, the specimens were kept in the moulds for $24 \mathrm{~h}$ in a humid chamber. Once unmoulded, they were cured in airtight containers with a solution of sodium hydroxide of $1 \mathrm{~mol}$ per $\mathrm{kg}$ of water at room temperature during 27 days. Finally, the containers were introduced in an oven at $60^{\circ} \mathrm{C}$ until the end of the test. The sodium hydroxide solution kept the specimens saturated and prevented a depletion of alkalis in the cement paste. During both stages, specimen length was measured regularly until the end of the test.

Once in the oven at $60^{\circ} \mathrm{C}$, the reactive specimens started to expand due to the formation of ASR products at the glass-cement paste interfaces. The test ended when the amount of reaction product at the interface was high enough to separate the glass disc from the cement paste matrix. From the length change measurements of the reactive and the control specimens, the expansion curves corresponding to the formation of ASR reaction products in a single glass-cement paste interface was obtained, assuming that the strains developed in the cement paste matrix of the reac-

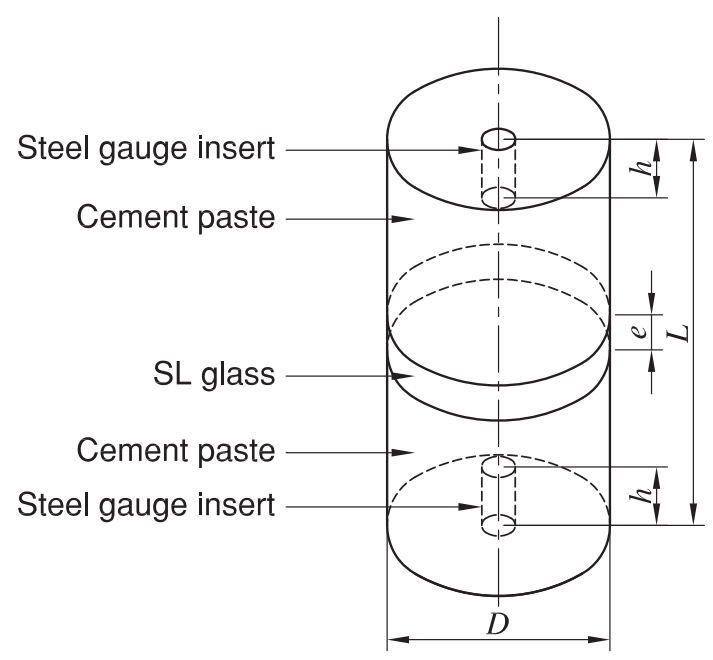

Fig. 1. Scheme of reactive specimens. Dimensions (in $\mathrm{mm}$ ): $D=33, L=66$, $h=10, e=6$.

tive specimens was the same as the one developed in the control specimens.

Complementarily, scanning electron microscopy coupled with energy dispersive X-ray spectroscopy (SEM/EDS) was employed to analyse the reaction products formed in reactive specimens tested in similar conditions.

\subsection{Specimen preparation}

\subsubsection{Reactive aggregate discs}

The SL glass discs were cut from 6 -mm-thick flat glass by means of a $\varnothing 35 \mathrm{~mm}$ diamond holesaw. The parallelism and the smoothness of the faces of the discs is guaranteed by industrial origin of the flat glass. The oxide composition of the SL glass was obtained from SEM/EDS analyses resulting in: $76.7 \mathrm{wt} \% \mathrm{SiO}_{2}, 11.1 \mathrm{wt} \%$ $\mathrm{CaO}, 5.0$ wt\% $\mathrm{Na}_{2} \mathrm{O}, 3.3$ wt\% $\mathrm{MgO}, 1.3$ wt\% $\mathrm{Fe}_{2} \mathrm{O}_{3}, 1.1$ wt\% $\mathrm{Al}_{2} \mathrm{O}$, $0.8 \mathrm{wt} \% \mathrm{SO}_{3}$, and $0.7 \mathrm{wt} \% \mathrm{~K}_{2} \mathrm{O}$. See Section 2.6 for details of the SEM/EDS setup.

\subsubsection{Cementitious matrix}

The Portland cement was type CEM I 42,5 N-SR5 according to the Spanish standard UNE-EN 197-1 [12]. The alkali content of the cement in terms of equivalent sodium oxide $\left(\mathrm{Na}_{2} \mathrm{O}_{e}\right)$ was $0.61 \mathrm{wt} \%$. The water-to-cement weight ratio of the cement paste was 0.47 . Sodium hydroxide $(\mathrm{NaOH})$ was added to the mixing water in order to increase the $\mathrm{Na}_{2} \mathrm{O}_{\mathrm{e}}$ content to $1.1 \mathrm{wt} \%$ of the cement weight.

\subsubsection{Moulds and gauge inserts}

The moulds and accessory pieces used for elaborating both reactive and control specimens were made in grey PVC according to the dimensions given in Fig. 2. The different uses of each piece in the elaboration process are described below. For the gauge inserts, standard M4 nickel-plated screw union, consisting of a male screw and a threaded sleeve, were used (Fig. 3). Before casting, a thin layer of mineral oil was applied to the interior of the moulds to facilitate the removal of the hardened specimens. Special care was taken in keeping the gauge inserts free of oil.

\subsubsection{Moulding of specimens}

Control and reactive specimens require different moulding procedures. The main difference is that each control specimen was completely cast in one single operation with cement paste from the same batch, while the reactive specimens had to be cast by 

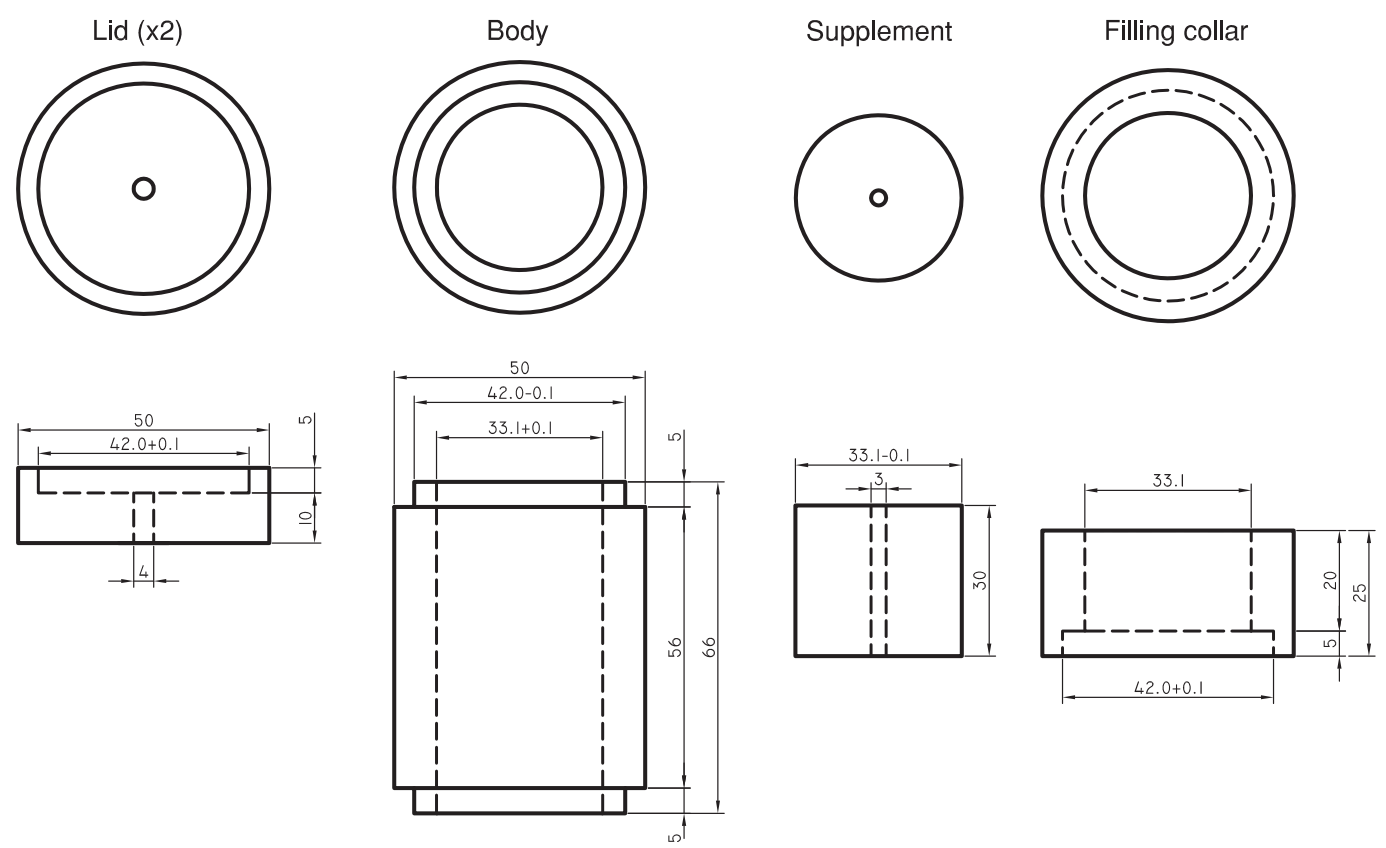

Fig. 2. PVC moulds and accessory pieces used for preparing specimens for interfacial expansion tests. Dimensions in mm.

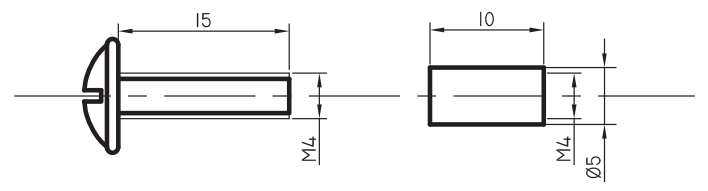

Fig. 3. Steel gauge inserts. Dimensions in $\mathrm{mm}$.

halves, the second half filled $24 \mathrm{~h}$ after the first one, therefore using cement paste from two different batches.

The moulding procedure for control specimens, illustrated in Figs. 4, was the following:

(a) Place the mould bottom lid with the gauge insert in position at the lower end of the mould. Place the filling collar at the upper end of the mould.

(b) Fill the first half of the mould with two approximately equal layers of cement paste, each layer being compacted with a tamper (a cylindrical steel rod of $\varnothing 5 \mathrm{~mm}$ and $150 \mathrm{~mm}$ length). Give a few strokes to the mould with the tamper to remove trapped air and smooth the surface. Repeat the procedure for the second half of the mould.

(c) Remove the filling collar, cut off the cement paste flush with the top of the mould and smooth the surface with a few strokes of the tamper.

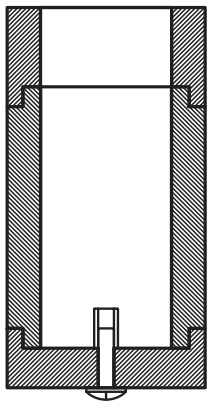

(a)

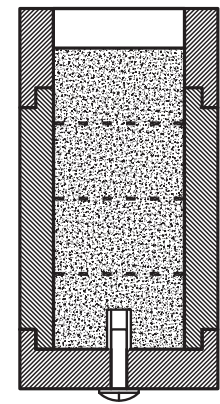

(b)

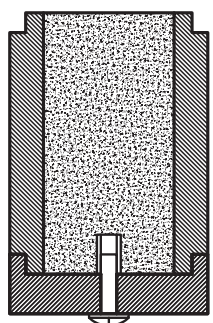

(c)

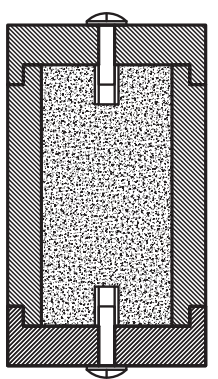

(d)

Fig. 4. Schematic elaboration sequence of control specimens. 


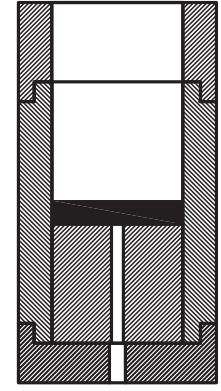

(a)

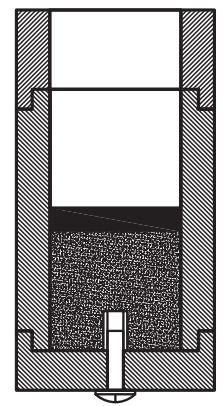

(e)

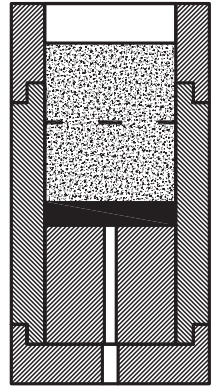

(b)

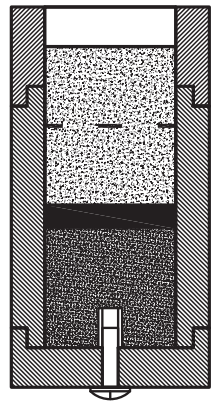

(f)

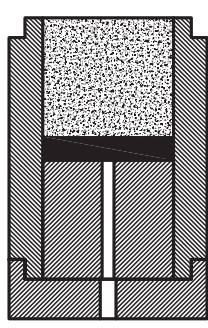

(c)

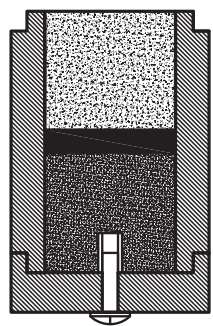

(g)

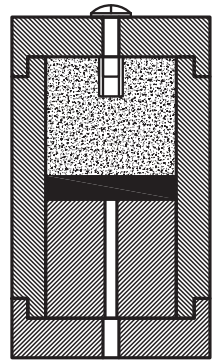

(d)

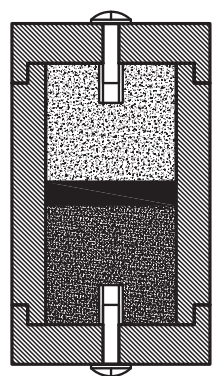

(h)

Fig. 5. Schematic elaboration sequence of reactive specimens.

(f) Proceed as described in (b).

(g) Proceed as described in (c).

(h) Proceed as described in (d).

The filling of the moulds was always completed within the first 10 min after preparing the mix.

In order to unmould the specimens, first the screws of the gauge terminals and, then, the top and bottom lids had to be removed. Next, the hardened specimens were extracted by means of the device schematically depicted in Fig. 6. Note that the pressure is not applied on the gauge terminal but on the outer corona of the specimen, preventing in that way a punching action.

\subsection{Alkaline bath}

Once unmoulded, the specimens were labelled with a permanent marker and introduced by pairs in airtight containers with alkaline solution. The containers were standard Gastronorm size GN 1/9 (1 L capacity) and made of polypropylene. The resulting volume proportion of alkaline solution to specimens in the container was then greater than 6 . The specimens were placed in ad hoc manufactured supports made of methacrylate and stainless steel, thought to ensure free access of the alkaline solution to the entire surface of the specimens and, therefore, to ensure that the specimens do not touch the sides of the container or each other.

The alkaline solution was prepared with $40 \mathrm{~g}$ ( $1 \mathrm{~mol})$ of $\mathrm{NaOH}$ and $2 \mathrm{~g}$ of $\mathrm{Ca}(\mathrm{OH})_{2}$ per $\mathrm{kg}$ of water, using tap water and USP grade $\mathrm{NaOH}$ and $\mathrm{Ca}(\mathrm{OH})_{2}$. The amount of $\mathrm{Ca}(\mathrm{OH})_{2}$ was sufficient to keep the alkaline bath calcium-saturated during both test stages.

For the curing stage, the containers were kept at room temperature. For the exposure stage, the containers were placed in an oven set at $60^{\circ} \mathrm{C}$, with a standard deviation of $\pm 1.2^{\circ} \mathrm{C}$.

\subsection{Length change measuring}

The length comparator used for determining the length change of the specimens features a dial micrometer with $2 \mu \mathrm{m}$ resolution.

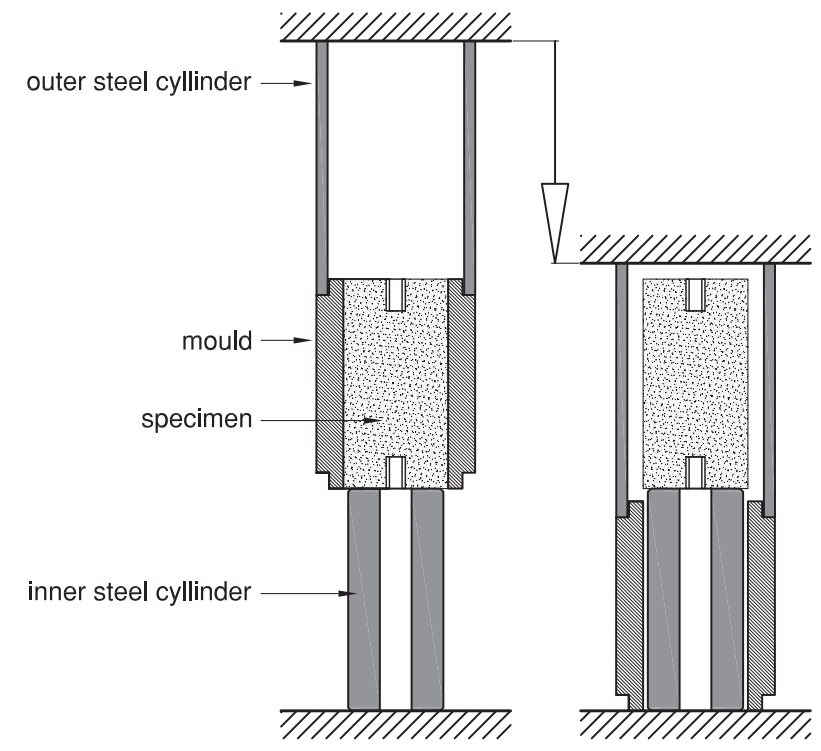

Fig. 6. Specimen extraction device.

The terminals of this device are tapered tips which are introduced in the gauge inserts of the specimen to be measured. A 66-mmlength reference bar made of Invar (nickel-iron alloy with a low coefficient of thermal expansion) is used for checking the device at regular intervals. The length comparator was placed beside the oven, in order to minimize the time needed for measuring.

The general procedure for measuring the length changes of the specimens was the following:

(a) Place the reference bar in the length comparator. If necessary, reset the dial gauge of the micrometer.

(b) Remove the containers from the storage location (the oven for the exposure stage) one at a time. 
(c) Remove the first specimen from the alkaline bath and dry its surface with absorbent paper.

(d) Place the specimen in the length comparator and take the reading immediately. Leave the specimen on a tray, and repeat for the second specimen.

(e) Return both specimens to the container. Verify that the specimens are completed cover with alkaline solution before returning the container to the storage location; otherwise, refill it.

After unmoulding and before taking the first readings (zero readings), the specimens were kept for $30 \mathrm{~min}$ in the containers with alkaline solution in order to guarantee that the specimens were at room temperature. Otherwise the specimens temperature could have been somewhat higher due to the heat released by the cement hydration.

\subsection{Calculations}

The current strain $\varepsilon$ of each control specimen is calculated according to the following expression:

$\varepsilon=\frac{l-l_{0}-2 h \alpha_{\text {steel }}\left(T-T_{0}\right)}{L-2 h}$

where $L[\mathrm{~m}]$ is the initial distance between inserts (see Fig. 1 ), $h[\mathrm{~m}]$ is the length of the gauge inserts, $l_{0}$ and $l[\mathrm{~m}]$ are the initial and the current readings of the dial indicator, respectively, $\alpha_{\text {agg }}\left[1 /{ }^{\circ} \mathrm{C}\right]$ is the linear thermal expansion coefficient of the gauge inserts steel, $T$ and $T_{0}\left[{ }^{\circ} \mathrm{C}\right]$ are the current and initial temperature of the specimen, respectively. Then, the interfacial expansion at each interface of a reactive specimen, $d_{I}[\mathrm{~m}]$, is calculated as

$2 d_{I}=\left(l-l_{0}\right)-\bar{\varepsilon}(L-2 h-e)-\left(e \alpha_{\text {agg }}+2 h \alpha_{\text {steel }}\right)\left(T-T_{0}\right)$

where $\bar{\varepsilon}$ is the averaged strain measured in the corresponding control specimens set, $e[\mathrm{~m}]$ is the thickness of the glass disc, and $\alpha_{a g g}$ $\left[1 /{ }^{\circ} \mathrm{C}\right]$ is the linear thermal expansion coefficient of the glass.

\subsection{SEM images and EDS analyses}

The samples for the SEM/EDS were cut with a diamond saw with a width of approximately $10 \mathrm{~mm}$ and then put in vacuum desiccator for two days. After drying, the samples were impregnated with a low viscosity epoxy resin. Once the epoxy was cured, the upper 1-2 mm were cut with a low speed precision diamond saw. The new exposed surfaces were ground and polished with abrasive grains successively finer, starting with $15 \mu \mathrm{m}$ and finishing with $1 \mu \mathrm{m}$. In order to avoid leaching, all the grinding and polishing operations were done using polishing oil instead of water. The analyses were performed with an ESEM FEG XL30. The carbon coated samples were studied in the high vacuum mode with an accelerating voltage of $12 \mathrm{kV}$ and a beam current of $272-275 \mu \mathrm{A}$. The chemical composition of the reaction products was analysed with EDX using point spectra. An EDAX 194 UTW detector, a Philips digital controller, and Genesis Spectrum Software (Version 4.6.1) with ZAF corrections were used.

\section{Results}

\subsection{Interfacial expansions}

The strain curves calculated according to Eq. (1) for the three control specimens tested are shown in Fig. 7. The vertical dashed line indicates the end of the curing stage and the beginning of the exposure stage. The red line indicates the average strain of the three specimens. This average strain was used for the calcula-

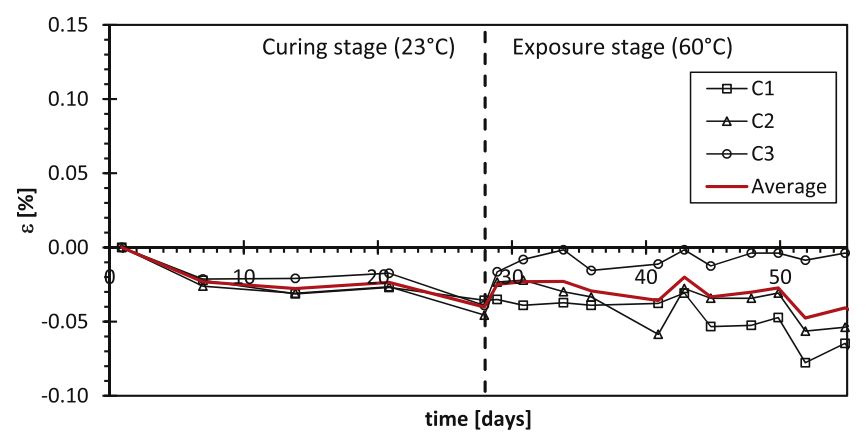

Fig. 7. Strain curves of control specimens. The red line represents the average strain curve of the three tested specimens.

tion of the interfacial expansions of the three reactive specimens, according to Eq. (2). During both stages, the control specimens showed an overall shrinking behaviour, only interrupted by the thermal expansion when the specimens were introduced in the oven at $60^{\circ} \mathrm{C}$ (Fig. 7).

The interfacial expansions of the reactive specimens are shown in Fig. 8, where the continuous red line represents the average interfacial expansion curve of the three reactive specimens tested. During the curing stage there were practically no interfacial expansions, but once in the oven at $60^{\circ} \mathrm{C}$, the reactive specimens started to expand. These expansions are attributed to the formation of ASR products at the glass-cement paste interfaces. The tests finished when the amount of reaction product at the interfaces was high enough to separate the glass from the cement paste, something that happened for interfacial expansion values of about $30 \mu \mathrm{m}$. In order to highlight the importance of deducting the strains of the cement paste matrix, an additional red-dashed curve is plotted in Fig. 8. This curve represents the average interfacial expansions but calculated without deducting the strains of the cement paste matrix, i.e. with $\bar{\varepsilon}=0$ in Eq. (2).

\subsection{Reaction products}

Fig. 9 shows a set of images of the interfacial zone of a SL glasscement paste reactive specimen tested in similar conditions. In the left image, the upper part corresponds to the glass, the bottom part to the cement paste, and the middle part to the reaction products. The reaction products themselves can only be seen at the limits of this zone, just besides the cement paste and the glass. The rest is plain black due to the epoxy resin used in the preparation of the sample. It is assumed that reaction products had been there but due to the cutting and polishing processes they were lost. A similar

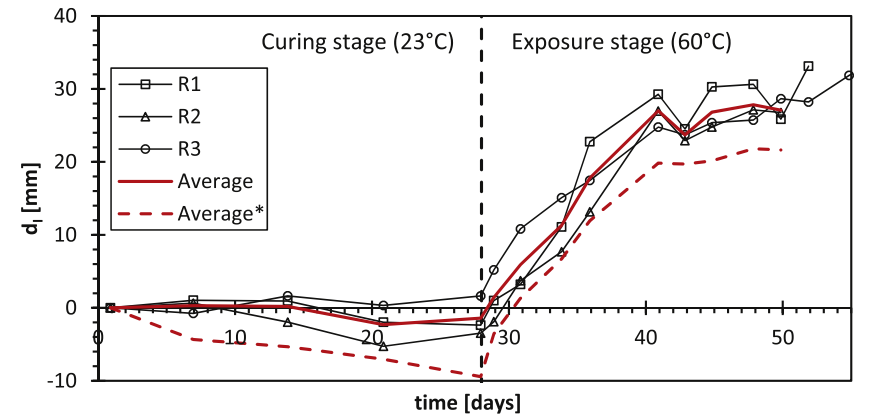

Fig. 8. Interfacial expansion curves of reactive specimens. The continuous red line represents the average interfacial expansion curve of the three tested specimens. The dashed red line represents the average interfacial expansion curve calculated without deducting the strains of the cement paste matrix. 


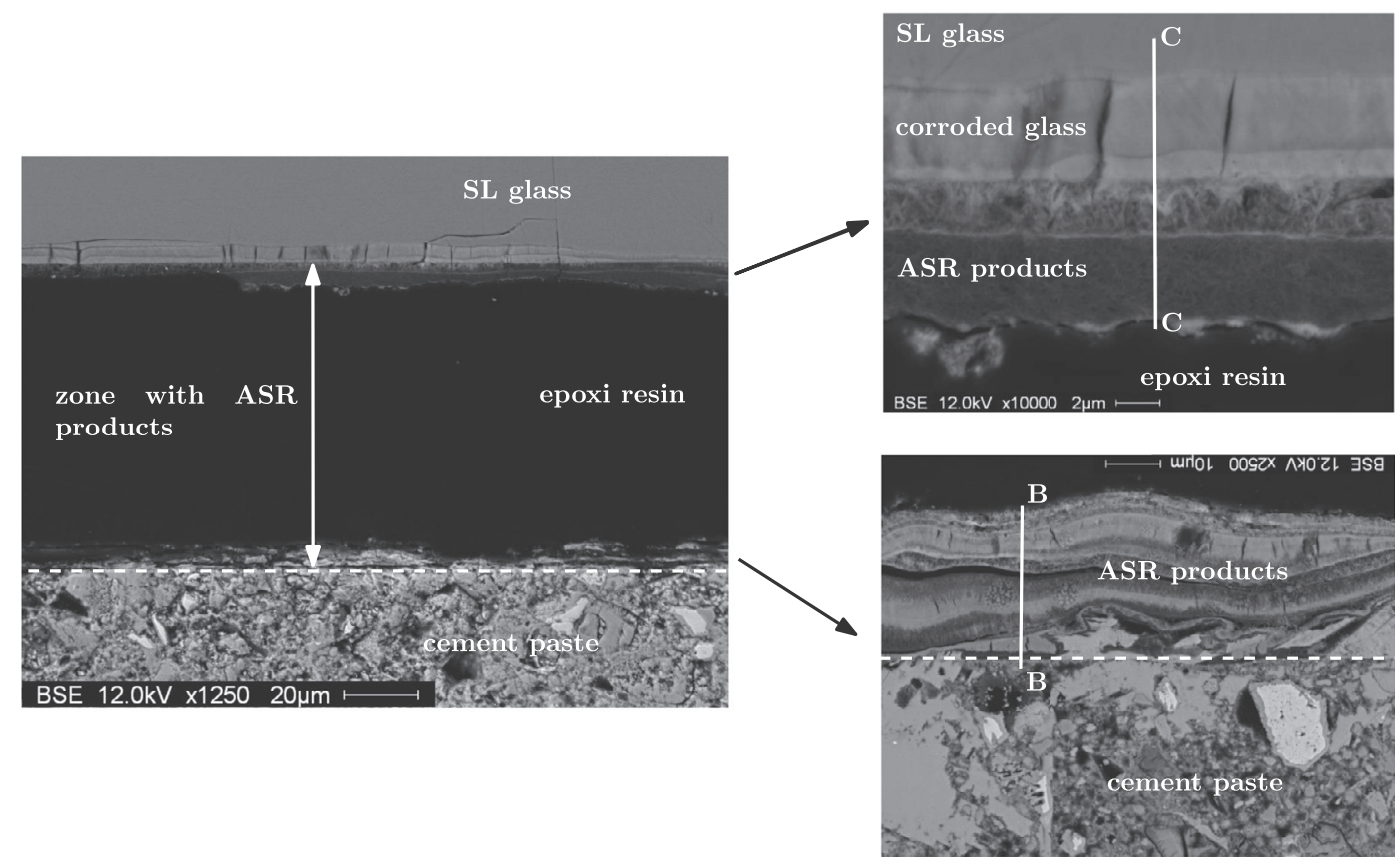

Fig. 9. SEM images from the reacted interfacial zone of an active specimen made of cement paste and SL glass.

configuration can be seen in the SEM images obtained by Yi and Ostertag [13] for mortar-borosilicate glass interfaces. In the upper-right image, the corrosion process of the glass can be appreciated in detail, from the intact glass to the ASR product. In the bottom-right image, the original position of the interface can be clearly distinguished as a straight line separating the mortar from the ASR products. Note that the morphology of the reaction products located next to the cement paste is quite different from that observed next to the glass.

The composition of the reaction products was investigated by means of EDS analysis performed in equally separated points along the lines $\mathrm{C}-\mathrm{C}$ and $\mathrm{B}-\mathrm{B}$ (Fig. 9). In Fig. 10 and 11, the profiles obtained of the molar $\mathrm{Ca} / \mathrm{Si}$ - and $(\mathrm{Na}+\mathrm{K}) / \mathrm{Si}$-ratio are presented. The profile $\mathrm{C}-\mathrm{C}$ (next to the glass) can be divided in five sectors: (I) points on the epoxy resin with an erratic composition; (II) $\mathrm{Ca}$ / $\mathrm{Si} \approx 1.3$ and $(\mathrm{K}+\mathrm{Na}) / \mathrm{Si} \approx 0.2-0.3$; (III) $\mathrm{Ca} / \mathrm{Si} \approx 1.0-1.1$ and $(\mathrm{K}+\mathrm{Na}) /$ $\mathrm{Si} \approx 0.1$; (IV) transition between composition of sector III and V; (V) glass composition.

In the profile $\mathrm{B}-\mathrm{B}$ (next to the cement paste) different sectors can also been distinguished: (I) cement paste composition, $\mathrm{Ca}$ / $\mathrm{Si} \approx 1.7$ and $(\mathrm{Na}+\mathrm{K}) / \mathrm{Si} \approx 0.25 ; \quad(\mathrm{II}) \mathrm{Ca} / \mathrm{Si} \approx 1.2-1.4$ and $(\mathrm{K}+\mathrm{Na}) /$ $\mathrm{Si} \approx 0.2-0.3$; (III) $\mathrm{Ca} / \mathrm{Si} \approx 1.2-1.4$ and $(\mathrm{K}+\mathrm{Na}) / \mathrm{Si} \approx 0.3-0.8$; (IV) $\mathrm{Ca} /$ $\mathrm{Si} \approx 1.3-1.1$ and $(\mathrm{K}+\mathrm{Na}) / \mathrm{Si} \approx 0.2-0.4 ;(\mathrm{V}) \mathrm{Ca} / \mathrm{Si} \approx 1.2$ and $(\mathrm{K}+\mathrm{Na}) /$ $\mathrm{Si} \approx 0.1-0.2$; (VI) points on the epoxy resin with a erratic composition.

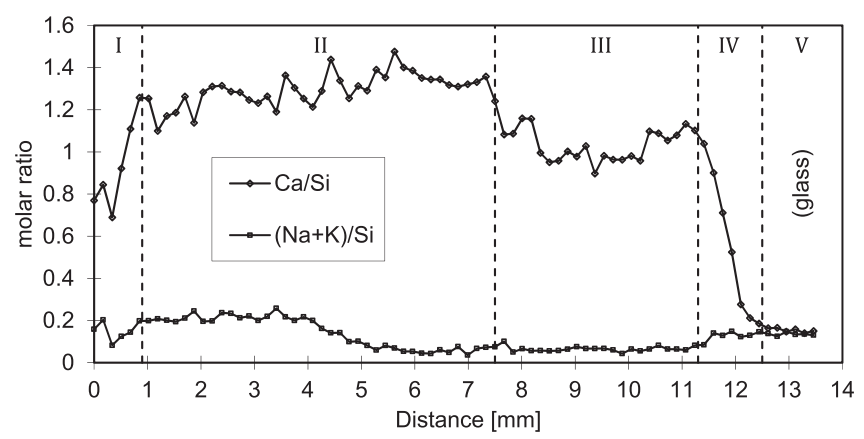

Fig. 10. Profile of the molar $\mathrm{Ca} / \mathrm{Si}-$ and $(\mathrm{Na}+\mathrm{K}) / \mathrm{Si}$-ratios along line $\mathrm{C}-\mathrm{C}$ of Fig. 9.

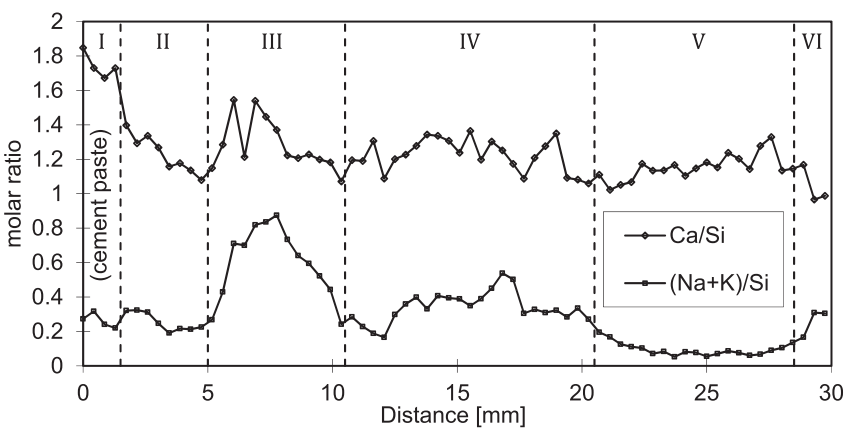

Fig. 11. Profile of the molar $\mathrm{Ca} / \mathrm{Si}-$ and $(\mathrm{Na}+\mathrm{K}) / \mathrm{Si}$-ratios along line $\mathrm{B}-\mathrm{B}$ of Fig. 9.

\subsection{Discussion}

In the SEM images presented (Figs. 9), the original position of the interface is clearly distinguished as a straight line dividing the 'unaltered' cement paste from the zone with reaction products. On the glass side, in contrast, the limit is more diffuse, with a layer of about 5 to $10 \mu \mathrm{m}$ in which the glass exhibited cracks and a degraded aspect.

In general, the observed ASR products exhibited a layered structure, i.e. reaction products of different morphology and/or composition appeared alternated in layers parallel to the original glassmatrix interface. This indicates that, as the reaction products precipitate, the conditions for the formation of new products change, probably due to the formation of diffusion barriers that altered the supply of reactants. Layered ASR products have also been observed by other authors. In a study on the reactivity of Pyrex (borosilicate) glass rods embedded in mortar, Yi and Ostertag [13] reported distinctively banded distributions of $\mathrm{Ca}$ - and Na-rich gels around the Pyrex rods. In another study, Bleszynski and Thomas [14] found a layered structure of reaction products with different morphology and composition in concretes made with reactive flint aggregates.

The range of compositions of the reaction products observed in the SL glass specimens $(\mathrm{Ca} / \mathrm{Si}=1.00-1.50,(\mathrm{Na}+\mathrm{K}) / \mathrm{Si}=0.10-0.80)$ is similar to the one observed by Rajabipour et al. $[15,16]$ sur- 
rounding SL glass particles in mortar specimens made with crushed SL glass aggregates $(\mathrm{Ca} / \mathrm{Si}=1.34-1.51, \mathrm{Na} / \mathrm{Si}=0.06-0.29)$. Rajabipour et al. referred to this product as 'pozzolanic CSH', differentiating it from the products with lower calcium content $(\mathrm{Ca} /$ $\mathrm{Si}=0.29-0.37,(\mathrm{Na}+\mathrm{K}) / \mathrm{Si}=0.38-0.42)$ formed within cracks in the glass particles, which were called 'ASR gel'. The pozzolanic $\mathrm{CSH}$ was regarded by the authors as a non-expansive product, attributing the observed expansion of the mortar uniquely to the ASR gel. This distinction between calcium-rich products with low swelling capacity and calcium-poor products with high swelling capacity has been also made by other authors, e.g. [17-19].

Our results, however, indicate that the so-called 'pozzolanic CSH' seems also to be capable of developing significant expansions. The cause of this apparent contradiction may be found in the different mechanical restraint in each of the tests reported. In the case of glass particles in mortar, the pozzolanic CSH needs to be able to generate cracks in the cementitious matrix in order to induce measurable expansions in concrete. In contrast, in the case of the interfacial expansion tests the pozzolanic CSH only needs to be able to detach the cementitious matrix-glass interface in order to develop measurable expansions. In other words, in the first case the pozzolanic CSH needs to develop a swelling-pressure ${ }^{1}$ capable of propagating cracks in the cementitious matrix, while in the second case it only needs to develop a swelling-pressure capable of overcoming the tensile strength of the cementitious matrix-glass interface, which is expected to be significantly lower. Then, we may conjecture that the formation of pozzolanic CSH is in nature an expansive reaction that can be inhibited by a superimposed pressure equal or greater than its maximum swelling-pressure. At this point, it must be noted that although the pozzolanic CSH is treated as a homogeneous phase, at a lower scale of observation distinct low- and high-calcium layers, with different swelling potentials, may probably be distinguished.

\section{On ASR expansions in SL glass concrete}

In this section, available experimental evidence on ASR expansion in SL glass concrete is contrasted with the interfacial expansion results presented in Section 3, in order to propose a ASR reaction-expansion mechanism capable of explaining the different experimental observations.

\subsection{Experimental evidence}

SL glass is an amorphous material composed of silica tetrahedral units, connected to each other by bridging oxygens, or to other atoms, mainly $\mathrm{Na}, \mathrm{Ca}$ and $\mathrm{H}$, through non-bridging oxygens [20]. In contact with highly alkaline solutions, as the cement pore solution, SL glass dissolves mainly into aqueous $\mathrm{Si}, \mathrm{Na}$ and $\mathrm{Ca}$ species due to the nucleophilic attack of hydroxyl ions $\left(\mathrm{OH}^{-}\right)$, in a process similar to the one described by Rajabipour et al. [21] for generic metastable silica. These aqueous species eventually react between themselves and with other aqueous species already present in the pore solution forming Calcium-Alkali-Silica-Hydrates (C-R-S$\mathrm{H})$ of variable composition. In SL glass concrete, these dissolution and formation reactions may occur both at the glass-cement interfaces and within cracks inside the glass particles. Depending on various factors, the formation of $\mathrm{C}-\mathrm{R}-\mathrm{S}-\mathrm{H}$ may eventually lead to beneficial or harmful effects on concrete.

For instance, several studies have demonstrated that if SL glass is ground to particle sizes similar to those of regular Portland cement $(<100 \mu \mathrm{m})$, it exhibits pozzolanic behaviour, e.g. [6,22-27]. That means that if it is used as partial replacement of Portland

\footnotetext{
${ }^{1}$ Swelling pressure is defined as the pressure developed by the formation of ASR products under constant volume conditions.
}

cement, the ground SL glass slowly reacts with the calcium hydroxide resulting from the clinker hydration gradually forming secondary hydration products $(\mathrm{C}-\mathrm{R}-\mathrm{S}-\mathrm{H})$ with $\mathrm{Ca} / \mathrm{Si}$ molar ratios around 1.5 , commonly referred in the literature as 'pozzolanic CSH'. These secondary products fill the large capillary voids around the SL glass particles with consequent reduction of porosity and refinement of the pore sizes, thus improving the strength and decreasing the permeability of the system. The formation of pozzolanic CSH has not been found to induce deleterious expansions in concrete. On the contrary, the use of ground glass as a partial replacement of cement has been found effective for reducing the potential of ASR expansions in concrete prepared with natural reactive aggregates [23], similarly to other pozzolans.

On the other hand, the use of crushed SL glass as replacement of natural aggregates (particle size $>0.5 \mathrm{~mm}$ ) has been demonstrated to be very pernicious for concrete due to the development of ASR expansions, e.g. [28,29,15,24]. Rajabipour and co-workers [15] explain the different results obtained with ground and crushed SL glass particles based on the presence of microcracks in the latter. These authors found that, at the interface between the crushed SL glass particles and the cement paste, a diffuse layer of C-R-S-H of a thickness up to about $20 \mu \mathrm{m}$ had developed with similar composition to the one formed in the pozzolanic reaction of ground SL glass $(\mathrm{Ca} / \mathrm{Si} \approx 1.4,(\mathrm{Na}+\mathrm{K}) / \mathrm{Si} \approx 0.2)$. In contrast, they found that the $\mathrm{C}-\mathrm{R}-\mathrm{S}-\mathrm{H}$ formed within the glass microcracks had lower $\mathrm{Ca} / \mathrm{Si}$ ratios of around 0.3 and $(\mathrm{Na}+\mathrm{K}) / \mathrm{Si} \approx 0.4$. In a subsequent work, Maraghechi et al. [16] found that this low-calcium C-R-S-H is only formed within pre-existing cracks wider than $2.5 \mu \mathrm{m}$. Moreover, they found that only crushed SL glass particles with sizes greater than $0.3 \mathrm{~mm}$ have cracks wider than $2.5 \mu \mathrm{m}$, i.e. they found no low-calcium C-R-S-H associated with ground glass particles.

These observations motivated the conjecture that the highcalcium (pozzolanic) $\mathrm{C}-\mathrm{R}-\mathrm{S}-\mathrm{H}$ is not expansive, and that the deleterious expansions found in concrete made with crushed SL glass is only due to the formation of highly expansive low-calcium C-R-S$\mathrm{H}$ (referred as 'ASR gel') within pre-existing microcracks inside glass particles wider than $2.5 \mu \mathrm{m}$. In order to confirm this conjecture, the authors performed a second set of tests in which the microcracks of the crushed SL glass particles were healed by annealing at $650{ }^{\circ} \mathrm{C}[16]$. As a result, the ASR expansions practically disappeared, thus confirming the determinant role of microcracks in the ASR expansions of crushed SL glass concrete. Similarly, when using crack-free SL glass beads in Portland cement mortars, no low-calcium C-R-S-H (ASR gel) was observed [20]. Other authors also observed that in the absence of pre-existing cracks no lowcalcium products are formed [30].

According to Rajabipour, Maraghechi and co-workers, the presence of portlandite at the glass-cement paste interface prevents the formation of expansive low-calcium $\mathrm{C}-\mathrm{R}-\mathrm{S}-\mathrm{H}$ and favours the formation of high-calcium C-R-S-H $[15,16]$. This seems to be confirmed by the fact that when 'SL glass aggregates were used in alkali activated fly ash mortars, which do not form solid $\mathrm{Ca}$ $(\mathrm{OH})_{2}$ ', low-calcium C-R-S-H 'was observed both within the interior and at the surface of glass aggregates' [20].

The absence of C-R-S-H within cracks thinner than $2.5 \mu \mathrm{m}$ is explained by the fact that the diffusivity and permeability of cracks grow with the crack width [31-33]. Since the initiation and propagation of ASR depend on the diffusion of ionic reactants, as well as on the permeation of water inside the microcracks, the ASR rate within very thin cracks may be significantly slower, to the point that $\mathrm{C}-\mathrm{R}-\mathrm{S}-\mathrm{H}$ did not form within the testing time in quantities that were detectable by SEM [16].

In his doctoral thesis, the first author of the present paper has made similar observations in SEM/EDS analyses of a crushed SL glass concrete specimen after an accelerated confined ASR expansion test [11]. See for instance the SEM images of Fig. 12, where 

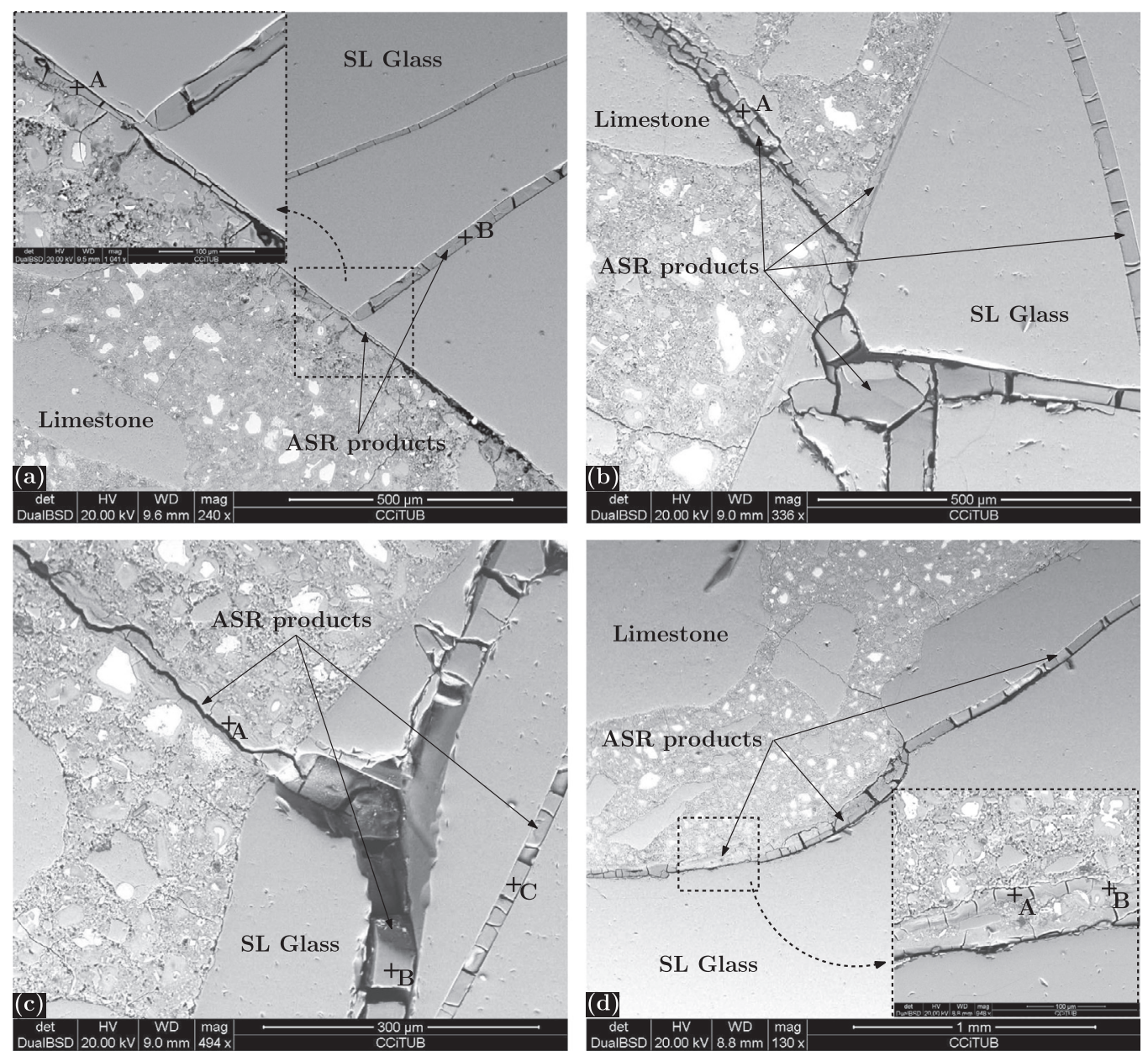

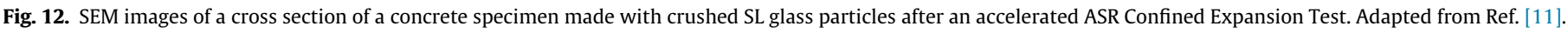

some of the points analysed via EDS are indicated on the images and the obtained chemical compositions (normalized to $\mathrm{Si}, \mathrm{Ca}, \mathrm{Na}$ and $\mathrm{K}$ ) are given in Table 1 . In those analyses, low-calcium products $(\mathrm{C}-\mathrm{R}-\mathrm{S}-\mathrm{H}$ with molar $\mathrm{Ca} / \mathrm{Si} \approx 0.3$ ) were only found within cracks inside glass particles. From these SEM images one can infer that the swelling of these low-calcium products produced wedging stresses that propagated cracks towards the limestone mortar with the same orientation as the gel-filled residual cracks inside the glass particles (Fig. 12c). In other cases, internal restrictions and differential mechanical properties of glass, ITZ and mortar induced more intricate cracking paths (Figs. 12b and d). The induced cracks in the limestone mortar were not initially filled with ASR products, but they were filled with intermediate and/or high-calcium products (C-R-S-H with molar $\mathrm{Ca} / \mathrm{Si} \approx 0.5-1.4)$ as the ASR progressed. In contrast with the observations of Rajabipour et al. [15], in most SEM images the glass-cement paste interface appears clean and does not show evidence of ASR products. In the few cases where a significant amount of ASR products was found at a glasscement paste interface, it was usually connected to a glass crack (see for instance Fig. 12a, b, and d), indicating the separation of the glass from the cement paste at this sites was due to the propagation of the glass crack filled with low-calcium products rather than due to the formation of calcium-rich products at the glasscement paste interface itself. These observations seem to confirm

Table 1

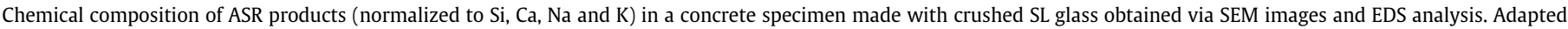
from Ref. [11].

\begin{tabular}{|c|c|c|c|c|c|c|c|c|}
\hline \multirow[t]{2}{*}{ Figure } & \multirow[t]{2}{*}{ Point } & \multirow[t]{2}{*}{ Location } & \multicolumn{6}{|c|}{ Composition (at.\%) } \\
\hline & & & $\mathrm{Si}$ & $\mathrm{Na}$ & K & $\mathrm{Ca}$ & $\mathrm{Ca} / \mathrm{Si}$ & $(\mathrm{Na}+\mathrm{K}) / \mathrm{Si}$ \\
\hline $12 \mathrm{a}$ & A & Glass-cement interface & 55.6 & 8.6 & 9.4 & 26.4 & 0.48 & 0.32 \\
\hline $12 \mathrm{a}$ & B & Glass crack & 63.2 & 8.6 & 7.9 & 20.4 & 0.32 & 0.26 \\
\hline $12 b$ & A & Limestone crack & 61.7 & 6.7 & 4.6 & 27.0 & 0.44 & 0.18 \\
\hline $12 \mathrm{c}$ & A & Cement paste crack & 48.5 & 4.6 & 2.9 & 43.9 & 0.91 & 0.16 \\
\hline $12 c$ & B & Glass crack & 66.3 & 8.9 & 6.4 & 18.3 & 0.28 & 0.23 \\
\hline $12 \mathrm{c}$ & C & Glass crack & 65.8 & 9.6 & 6.9 & 17.7 & 0.27 & 0.25 \\
\hline $12 d$ & A & Cement paste crack & 56.9 & 7.3 & 8.1 & 27.7 & 0.49 & 0.27 \\
\hline $12 d$ & B & Cement paste crack & 48.8 & 6.2 & 5.2 & 39.8 & 0.82 & 0.23 \\
\hline
\end{tabular}


the proposition by Rajabipour et al. [15] that the ASR products formed at glass-cement interfaces are not expansive.

However, in the Interfacial Expansion Tests described in previous Section 3, well differentiated layers of reaction products were observed at glass-cement paste interfaces (Fig. 9). The molar $\mathrm{Ca} / \mathrm{Si}$ ratios measured in these products ranged from 1.0 to 1.5 (Figs. 10 and 11), which are somehow lower than the calcium content of the pozzolanic CSH reported by Rajabipour et al. [15], but, in any case, much higher than the calcium content of the reaction products within cracks. Moreover, the interfacial expansion curves obtained (Fig. 8) demonstrate that the reaction products rich in calcium are capable of developing significant expansions, in marked contradiction with the above mentioned proposition by Rajabipour et al. [15] that calcium-rich products are not expansive.

In any case the contrast between the well differentiated, expanding layers of calcium-rich ASR products developed in the Interfacial Expansion Tests (Fig. 9) and the diffuse, nonexpanding layers reported by Rajabipour et al. [15], or the seemingly absence of ASR products at the glass-cement paste interfaces observed in Fig. 12 is remarkable. In the latest case the difference is more striking since the specimen was prepared with the same SL glass, the same cement, the same $\mathrm{w} / \mathrm{c}$ ratio and the same initial alkali content as the specimen used for Interfacial Expansion Tests. Moreover, both specimens were tested with practically the same alkaline bath $\left(1 \mathrm{~m} \mathrm{NaOH}\right.$ solution) and temperature $\left(60^{\circ} \mathrm{C}\right)$. Thus, it may be expected that the chemical and micro-structural (porosity, solid fractions, bonding strength, etc.) conditions for ASR at the glass-cement paste interfaces had been similar in both cases, and, therefore, the differences in the resulting ASR products can not be explained by those factors.

\subsection{Reaction-expansion mechanism for SL glass concrete}

This inconsistency can be overcome if, instead of considering them as 'expansive' or 'not expansive', the low- and high-calcium products are differentiated in terms of the maximum swellingpressure (MSP) that they can exert. In this sense, it can be conjectured that the high-calcium products (the pozzolanic CSH) is capable of developing swelling-pressures high enough to separate the glass-cement interfaces in Interfacial Expansion Tests, but not high enough to separate the glass-cement interfaces of glass particles within concrete due to the additional resistance of the surrounding cementitious matrix. Consequently, in the first case the interfacial expansions continued 'indefinitely' while in the second case they are somehow inhibited by the mechanical restraint exerted by the cementitious matrix.

Analogous considerations can be done for the low-calcium product formed within cracks inside glass particles. As it has been observed [34] in accelerated ASR expansion tests under triaxial confinement, the ASR expansion rate of crushed SL glass concrete is reduced for increasing confining pressure. In these tests, the maximum applied pressure of $9 \mathrm{MPa}$ was not enough to totally inhibit the expansion. However, the authors estimated by extrapolation of the results obtained, that a confining pressure $\bar{\sigma}_{v} \approx 10$ MPa would be capable of inhibiting ASR expansions. Therefore, it can be inferred that the low-calcium products have also a MSP which, according to the results of Liaudat et al. [34], would have a lower bound of about $10 \mathrm{MPa}$. Note that this MSP has to be greater than $\bar{\sigma}_{v}$, because it has to simultaneously overcome $\bar{\sigma}_{v}$ and the tensile strength of the solid skeleton surrounding the reaction sites.

For given temperature and Relative Humidity (RH), the MSP has to be regarded as a property of each type of reaction product, while the $\bar{\sigma}_{v}$ has to be regarded as property of the particular reactive concrete considered. The MSP depends on the hydrophilic potential of the considered reaction product, and, consequently, it is expected to vary with its chemical composition (and probably also with temperature and $\mathrm{RH}$ ). The $\bar{\sigma}_{v}$ of a given concrete, in turn, obviously depends on the MSP of the different ASR products formed within the concrete, but also on the concrete meso-structure itself (strength of the cementitious matrix, amount and size distribution of aggregates, etc.), since that determines the internal restraint to the expansion of the ASR products.

These concepts can also be used for explaining why the ASR expansion rates are progressively reduced as the applied external pressure is increased [34]. Since the crushed glass particles used for preparing the specimens have different sizes, different shapes, and different residual cracks, and since these particles are randomly distributed within the cementitious matrix, it can be expected that the internal mechanical restraint at each reaction site will be different. Consequently, different external pressures are expected to be needed to inhibit the ASR expansions at each reaction site. Therefore, as the external pressure growths, the number of inhibited reaction sites increases, and the macroscopic expansion rate decreases.

For the proposed interpretation of the experimental evidence, the ASR products may be visualized as a space-filling gel composed by the aggregation of colloidal particles of $\mathrm{C}-\mathrm{R}-\mathrm{S}-\mathrm{H}$ of variable composition [21]. Two different fractions of water are distinguished in the ASR products: the water chemically bound in the $\mathrm{C}-\mathrm{R}-\mathrm{S}-\mathrm{H}$ and the water within the influence of absorbing forces, referred as 'gel water'. These absorbing forces can be attributed to different mechanisms (e.g. osmotic pressure [35], double-layer repulsive forces [17], surface forces of solid C-R-S-H [36]) but in any case they are expected to be dependent on the chemical composition of the $\mathrm{C}-\mathrm{R}-\mathrm{S}-\mathrm{H}$. The content of gel water determines the distance between the colloidal particles [21] and, consequently, the 'bulk' volume of the ASR product, i.e. increase as water is absorbed. If this swelling is prevented by the surrounding solid skeleton, a mechanical pressure will be exerted on the ASR gel (C-R-S-H + gel water) counteracting the absorption pressure and, consequently, the amount of gel water absorbed will be lower than in free swelling conditions. Conversely, if the mechanical restraint is removed the original potential of water absorption will be restored and the ASR products will swell. The gel water within the ASR products is regarded as part of the concrete pore solution, i.e. as an aqueous medium in which diffusion-reaction processes may occur. Then, changes in the amount of gel water are expected to have an effect on the reaction rates by locally reducing either the effective diffusion section, the 'wet' surface area of dissolving silica, or the volume of reacting medium.

In order to clarify the proposed expansion mechanism, in Fig. 13 the progressive formation of ASR products within a pre-existing crack inside a non-reactive aggregate is schematically represented. In the same figure, the qualitative evolutions of some significant parameters as functions of the amount of formed ASR products $\left(M^{R P}\right)$ are also presented, namely: the swelling-pressure $\sigma_{g}$, the gel porosity $\phi^{R P}$ (defined as the volume of gel water per unit volume of ASR products), the crack width $w$, and the total porosity $\phi$ (defined as the volume of pore solution - which includes free and gel water - per unit volume of crack). During the initial stages (Fig. 13, A-C), both sides of the crack are assumed to be fixed. Later, the upper side is released allowing it to move freely following the volume change of the ASR products.

The process starts with the diffusion of reactants into the crack, which eventually leads to the formation of colloidal C-R-S-H particles aggregated in a gel structure (Fig. 13A). Since the crack and the ASR products within it are assumed to remain always completely saturated with water, these ASR products initially coexist with the free water that fills the remaining empty space in the 

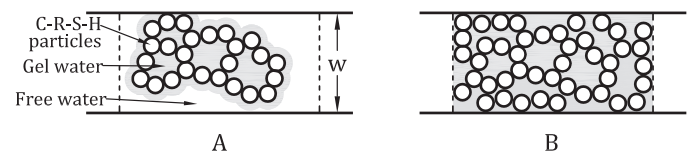

B

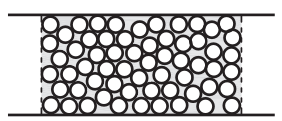

C

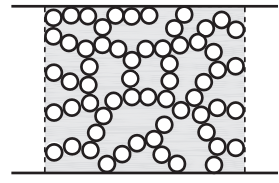

D
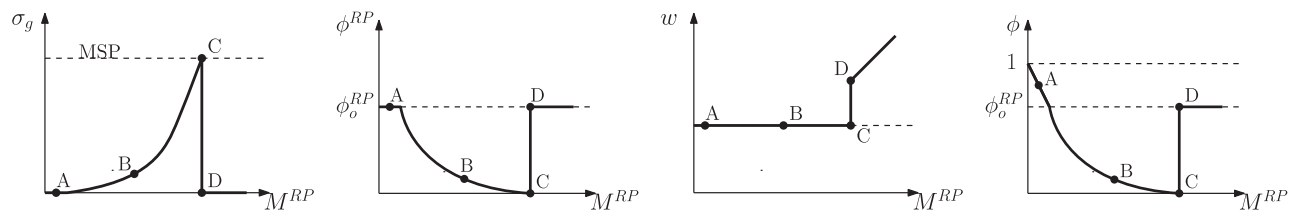

Fig. 13. Schematic representation of progressive formation of ASR products within a pre-existing crack inside a non-reactive aggregate.

crack. In this condition, the ASR products are unstressed and, thus, the gel porosity $\left(\phi_{o}^{R P}\right)$ is the maximum possible depending on the chemical composition of the $\mathrm{C}-\mathrm{R}-\mathrm{S}-\mathrm{H}$ particles.

As the reaction progresses (Fig. 13B), the free water volume is replaced by the ASR products and, consequently, the total porosity $(\phi)$ decreases linearly with the increasing amount of reaction products $\left(M^{R P}\right)$ until reaching the maximum gel porosity $\left(\phi_{o}^{R P}\right)$. From this point on, the formation of $\mathrm{C}-\mathrm{R}-\mathrm{S}-\mathrm{H}$ occurs at the expense of the gel water volume, i.e. the gel porosity of the ASR products is reduced. In this situation, the ASR products tend to swell in order to recover the maximum gel porosity, driven by absorbing forces $[17,35,36]$. However, since both sides of the crack are fixed, this is not possible and a swelling-pressure $\left(\sigma_{g}\right)$ is induced.

As more $\mathrm{C}-\mathrm{R}-\mathrm{S}-\mathrm{H}$ is formed, the gel/total porosity decreases and the swelling-pressure increases. When the gel porosity is exhausted (Fig. 13C), the MSP is reached. At this point, since there is no remaining pore solution, the formation of $\mathrm{C}-\mathrm{R}-\mathrm{S}-\mathrm{H}$ stops.

If now the upper side of the crack is released (Fig. 13D), the swelling-pressure disappears, and, thus, water is absorbed by the ASR products until recovering the maximum gel porosity. Consequently, the ASR products swell displacing the upper side of the crack. This swelling is expected to occur rapidly but not instantaneously since water would need some time to flow into the ASR products. Without any mechanical restraint, further formation of C-R-S-H implies a linear growth of the crack width with $M^{R P}$, with constant gel/total porosity, and without inducing swellingpressure.

It must be noted that the above-described mechanisms cannot explain by themselves the experimental results indicating that, when concrete is under anisotropic stress states, there is an increase of the ASR expansion rate(s) in the less compressed direction(s) that may be even higher than in free expansion conditions $[37,38,34]$. In order to explain this phenomenon, the effect of the concrete stress state on the orientation of the cracks induced by the formation of ASR products has to be considered. When ASR expansions occur in unloaded concrete, the induced cracks are oriented randomly, in patterns known as 'map cracking'. In contrast, when ASR expansions occur in loaded/restrained concrete, the induced cracks are aligned with the direction of the minor principal stress. Since cracks constitute preferential paths for the diffusion of reactants, the formation of reaction products within them is favoured in detriment of other locations, and, consequently, the expansion rate in the direction normal to the crack plane is accelerated. Additionally, the development of internal pressures due to the formation of reaction products, combined with the reduction of the material shear strength due to cracking, may result in an increase of the shear dilatancy in the less compressed directions (normal to the minor principal stress). These mechanisms are further discussed in a separated article devoted to the numerical modelling of ASR expansions in concrete.
Finally, it must be remarked that the proposed reactionexpansion mechanism establishes a source of coupling between the chemical reaction rates and the mechanical actions which not necessarily exclude other possible mechanisms acting simultaneously or alternatively. Moreover, the reaction mechanism as explained applies to SL glass concretes, where a considerable amount of alkalis is already present in the reacting aggregate. Similar mechanisms could apply to ASR with natural reactive aggregates, if the chemical environment at the reaction sites is comparable. This in particular could be true in the case of volcanites containing amorphous alkali-silica glass, but cannot be excluded for other types of aggregates.

\section{Concluding remarks}

A new experimental methodology for studying ASR expansions at the level of a single aggregate-cementitious matrix interface has been proposed. The methodology was used for measuring, seemingly for the first time, expansions occurring at the level of a single interface between SL glass and cement paste. Moreover, the composition and morphology of the formed ASR products were studied by means of SEM/EDS analyses. The results obtained indicate that the so-called 'pozzolanic CSH' (high-calcium ASR products) formed at SL glass-cement paste interfaces is capable of developing significant expansions when formed at reaction sites with low mechanical restraint. This conclusion is in contrast to other authors which refer to the high-calcium ASR products as non-expansive.

Based on the Interfacial Expansion Tests results, as well as on the theoretical and experimental results found in the literature, a reaction-expansion mechanism for ASR in SL glass concrete is proposed. This mechanism would be capable of reproducing the effect of applied loads and (internal or external) mechanical restraints in the development of ASR expansions.

Although the reaction-expansion mechanism as proposed in the paper applies to SL glass concrete, it may still have similarities with the ASR reaction-expansion mechanisms developed in concrete made with natural reactive aggregates.

\section{Declaration of Competing Interest}

The authors declare that there are no known conflicts of interest associated with this publication and there has been no significant financial support for this work that could have influenced its outcome.

\section{Acknowledgements}

This research is supported by grants BIA2016-76543-R from MEC (Madrid), which includes FEDER funds, and 2017SGR-1153 from AGAUR-Generalitat de Catalunya (Barcelona). The first author thanks the scholarship FPI (BES-2010-030515) from MEC (Madrid). 


\section{References}

[1] S. Diamond, N. Thaulow, A study of expansion due to alkali - silica reaction as conditioned by the grain size of the reactive aggregate, Cem. Concr. Res. 4 (4) (1974) 591-607.

[2] S. Multon, M. Cyr, A. Sellier, P. Diederich, L. Petit, Effects of aggregate size and alkali content on ASR expansion, Cem. Concr. Res. 40 (4) (2010) 508-516, https://doi.org/10.1016/j.cemconres.2009.08.002.

[3] C.F. Dunant, K.L. Scrivener, Effects of aggregate size on alkali-silica-reaction induced expansion, Cem. Concr. Res. 42 (6) (2012) 745-751, https://doi.org/ 10.1016/j.cemconres.2012.02.012.

[4] C. Zhang, A. Wang, M. Tang, B. Wu, N. Zhang, Influence of aggregate size and aggregate size grading on ASR expansion, Cem. Concr. Res. 29 (9) (1999) $1393-$ 1396.

[5] H. Reinhardt, O. Mielich, A fracture mechanics approach to the crack formation in alkali-sensitive grains, Cem. Concr. Res. 41 (3) (2011) 255-262, https://doi. org/10.1016/j.cemconres.2010.11.008.

[6] Y. Shao, T. Lefort, S. Moras, D. Rodriguez, Studies on concrete containing ground waste glass, Cem. Concr. Res. 30 (1) (2000) 91-100, https://doi.org/ 10.1016/S0008-8846(99)00213-6.

[7] Z.P. Bažant, A. Steffens, Mathematical model for kinetics of alkali-silica reaction in concrete, Cem. Concr. Res. 30 (3) (2000) 419-428.

[8] S. Poyet, A. Sellier, B. Capra, G. Foray, J.-M. Torrenti, H. Cognon, E. Bourdarot, Chemical modelling of Alkali Silica reaction: influence of the reactive aggregate size distribution, Mater. Struct. 40 (2) (2006) 229-239, https://doi. org/10.1617/s11527-006-9139-3.

[9] A. Carles-Gibergues, J.P. Ollivier, B. Fournier, M.-A. Bérubé, A new approach to the study of alkali-aggregate reaction mechanisms, in: M. Kawamura, K. Okada, S. Nishibayashi (Eds.), Proceedings of the 8th International Conference on Alkali-Aggregate Reaction in Concrete (ICAAR, Kyoto, Japan), Elsevier Applied Science, London, 1989, pp. 161-166.

[10] E. Schlangen, O. Çopuroğlu, Concrete damage due to Alkali-Silica reaction: a new method to determine the properties of the expansive gel, in: A. Carpinteri, P.G. Gambarova, G. Ferro, G. Plizzari (Eds.), Proceedings of the 6th International Conference on Fracture Mechanics of Concrete and Concrete Structures (FraMCoS-6, Catania, Italy, 17-22 June 2007), Taylor \& Francis, London, 2007, pp. 1835-1841.

[11] J. Liaudat, Experimental and Numerical Study of the Effect of Stress on ASR Expansions in Concrete, Universitat Politècnica de Catalunya (2018). Doctoral thesis, doi:hdl.handle.net/10803/620624.

[12] AENOR, Cement-Part 1: Composition, specifications and conformity criteria for common cements UNE-EN 197-1 (2011)..

[13] C. Yi, C. Ostertag, Mechanical approach in mitigating alkali-silica reaction, Cem. Concr. Res. 35 (1) (2005) 67-75, https://doi.org/10.1016/j. cemconres.2004.02.017.

[14] R.F. Bleszynski, M.D.A. Thomas, Microstructural studies of alkali-silica reaction in fly ash concrete immersed in alkaline solutions, Adv. Cem. Based Mater. 7 (2) (1998) 66-78, https://doi.org/10.1016/S1065-7355(97)00030-8.

[15] F. Rajabipour, H. Maraghechi, G. Fischer, Investigating the alkali-silica reaction of recycled glass aggregates in concrete materials, J. Mater. Civ. Eng. 22 (12) (2010) 1201-1208, https://doi.org/10.1061/(ASCE)MT.1943-5533.0000126.

[16] H. Maraghechi, S.-M.-H. Shafaatian, G. Fischer, F. Rajabipour, The role of residual cracks on alkali silica reactivity of recycled glass aggregates, Cem. Concr. Res. 34 (1) (2012) 41-47, https://doi.org/10.1016/j. cemconcomp.2011.07.004

[17] M. Prezzi, P.J.M. Monteiro, G. Sposito, The alkali-silica reaction, Part I: use of the double-layer theory to explain the behavior of reaction-product gels, ACI Mater. J. 1 (94) (1997) 10-16.

[18] A. Leemann, Alkali-Silica Reaction autogenous deformations and pressure development in a model system, in: T. Drimalas, J. Ideker, B. Fournier (Eds.), 14th International Conference on Alkali-Aggregate Reactions in Concrete, Austin, Texas, USA, 2012.

[19] A. Leemann, G. Le Saout, F. Winnefeld, D. Rentsch, B. Lothenbach, Alkali-silica reaction: the influence of calcium on silica dissolution and the formation of reaction products, J. Am. Ceram. Soc. 94 (4) (2011) 1243-1249, https://doi.org/ 10.1111/j.1551-2916.2010.04202.x.

[20] H. Maraghechi, F. Rajabipour, C.G. Pantano, W.D. Burgos, Effect of calcium on dissolution and precipitation reactions of amorphous silica at high alkalinity, Cem. Concr. Res. 87 (2016) 1-13, https://doi.org/10.1016/j. cemconres.2016.05.004

[21] F. Rajabipour, E. Giannini, C.F. Dunant, J.H. Ideker, M.D.A. Thomas, Alkali-silica reaction: current understanding of the reaction mechanisms and the knowledge gaps, Cem. Concr. Res. 76 (2015) 130-146, https://doi.org/ 10.1016/j.cemconres.2015.05.024.

[22] R. Idir, M. Cyr, A. Tagnit-Hamou, Use of fine glass as ASR inhibitor in glass aggregate mortars, Constr. Build. Mater. 24 (7) (2010) 1309-1312, https://doi. org/10.1016/j.conbuildmat.2009.12.030.

[23] A.M. Matos, J. Sousa-Coutinho, Durability of mortar using waste glass powder as cement replacement, Constr. Build. Mater. 36 (2012) 205-215, https://doi. org/10.1016/j.conbuildmat.2012.04.027.

[24] K. Afshinnia, P.R. Rangaraju, Influence of fineness of ground recycled glass on mitigation of alkali-silica reaction in mortars, Constr. Build. Mater. 81 (2015) 257-267, https://doi.org/10.1016/j.conbuildmat.2015.02.041.

[25] M. Kamali, A. Ghahremaninezhad, Effect of glass powders on the mechanical and durability properties of cementitious materials, Constr. Build. Mater. 98 (2015) 407-416, https://doi.org/10.1016/j.conbuildmat.2015.06.010.

[26] A. Omran, A. Tagnit-Hamou, Performance of glass-powder concrete in field applications, Constr. Build. Mater. 109 (2016) 84-95, https://doi.org/10.1016/ j.conbuildmat.2016.02.006.

[27] H. Du, K.H. Tan, Properties of high volume glass powder concrete, Cem. Concr

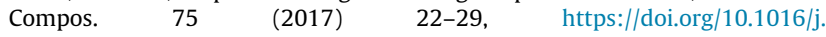
cemconcomp.2016.10.010.

[28] H. Zhu, W. Chen, W. Zhou, E.A. Byars, Expansion behaviour of glass aggregates in different testing for alkali-silica reactivity, Mater. Struct. 42 (4) (2008) 485494, https://doi.org/10.1617/s11527-008-9396-4.

[29] R.K. Dhir, T.D. Dyer, M.C. Tang, Alkali-silica reaction in concrete containing glass, Mater. Struct. 42 (10) (2009) 1451-1462, https://doi.org/10.1617/ s11527-008-9465-8.

[30] H. Du, K.H. Tan, Concrete with recycled glass as fine aggregates, ACI Mater. J 111 (1) (2014) 47-57. doi:10.14359.51686446.

[31] A. Djerbi, S. Bonnet, A. Khelidj, V. Baroghel-bouny, Influence of traversing crack on chloride diffusion into concrete, Cem. Concr. Res. 38 (6) (2008) 877-883, https://doi.org/10.1016/j.cemconres.2007.10.007.

[32] S.Y. Jang, B.S. Kim, B.H. Oh, Effect of crack width on chloride diffusion coefficients of concrete by steady-state migration tests, Cem. Concr. Res. 41 (1) (2011) 9-19, https://doi.org/10.1016/j.cemconres.2010.08.018.

[33] A. Akhavan, S.-M.-H. Shafaatian, F. Rajabipour, Quantifying the effects of crack width, tortuosity, and roughness on water permeability of cracked mortars, Cem. Concr. Res. 42 (2) (2012) 313-320, https://doi.org/10.1016/j. cemconres.2011.10.002.

[34] J. Liaudat, I. Carol, C.M. López, V.E. Saouma, ASR Expansions in Concrete under Triaxial Confinement, Cem. Concr. Compos. 86 (2018) 160-170, https://doi. org/10.1016/j.cemconcomp.2017.10.010.

[35] T. Powers, H.H. Steinour, An Interpretation of Published Researches on the Alkali-Aggregate Reaction, in: ACI Journal Proceedings, vol. 51, 1955, pp. 497516 and $785-812$.

[36] R.J. Kirkpatrick, A.G. Kalinichev, X. Hou, L.J. Struble, Experimental and molecular dynamics modeling studies of interlayer swelling: wate incorporation in kanemite and ASR gel, Mater. Struct. 38 (278) (2005) 449458, https://doi.org/10.1617/14344.

[37] C. Larive, Apports combinés de l'expérimentation et de la modélisation à la compréhension de l'alcali-réaction et de ses effets mécaniques, Doctoral thesis (in French), École Nationale des, Ponts et Chaussées (1997).

[38] B.P. Gautam, D.K. Panesar, S.A. Sheikh, F.J. Vecchio, Multiaxial expansion-stress relationship for alkali silica reaction-affected concrete, ACI Mater. J. 114 (1) (2017) 171-184, https://doi.org/10.14359/51689490. 